\title{
Healthcare Information System Based on Patient Service Quality
}

\author{
Ari Yulianti*, Muhardi \\ Faculty of Economy and Business \\ Universitas Islam Bandung \\ Bandung, Indonesia \\ *ari.yulianti169@gmail.com, muhardi.z66@gmail.com
}

\begin{abstract}
Similar as any other hospitals, the aim of Al-Mulk Hospital is to provide service on its patients with the best quality. One consistent effort practiced by this hospital is to provide technological advance and hospital management information system. Based on that, the objective of this research is to analyze the role of information system to improve patient service quality. This research was conducted with a descriptive qualitative method, by analyzing the implementation of management information system based on patient service quality. This research was conducted on a hospital in Sukabumi City, Indonesia. In this research, the required data was collected through informants that consist of hospital managers and patients. The existing condition of technology implementation and hospital management information system do not show optimum integration. Because of that, the hospital conducts continuous efforts to improve their information system so that it can be advanced and integrated, to finally improve their service quality. These efforts have actually provided a meaningful role or an added value in the efficiency of medical service, which also leads to the improvement of patient service quality.
\end{abstract}

Keywords-information system, hospital management, patients, service quality

\section{INTRODUCTION}

The hospital is a place of comprehensive public health services, not only for the cure of disease, but also the prevention of disease. Health service is an effort provided to patients who are healthy, therapeutic healing, or even prevention to maintain health. Hospitals must strive to provide the physical and non-physical infrastructure needed to provide the best service for the community. Therefore, it is compulsory for hospitals to provide physical facilities such as an Emergency Room (ER), outpatient room, inpatient room, and various other supporting facilities.

With the advancement of information technology and increasing public knowledge of the importance of health, it encourages hospitals to have a better management information system, which includes improving the quality of service and patient safety. Patients are the primary consumers for the hospital, therefore the implementation of information systems for patients is very important, not only for the purpose of convenience for patients, but also for the success of the hospital in providing the best for its service users.

The importance of information systems for patients is the concern of the researched hospital, as one of the hospitals located in a city. The location of this hospital is strategic, which is in the middle of the city so that it is easily accessible by regency and city communities. The existence of a strategic location and the readiness of the information system are considered as one of the factors that encourage the success of the quality of this hospital's services to the community who use its services.

Based on the numerous problems faced by this hospital, including offline information services which resulted in inefficient services provided to patients, the information system was not integrated in processing patient data between Emergency Room (ER), outpatient and inpatient care, and There are limited facilities and infrastructure, causing the quality of service to be less than optimal, one of the problems is the accumulation of patients waiting at registration. Another obstacle is the delay in finding medical record data for old patients, or patients with regular consultations to specialists or general practitioners. With these various weaknesses and service constraints, the hospital under study was encouraged to make service innovations, among which the objectives were to facilitate and assist the community using this hospital service, in obtaining priority health services and facilities for the Sukabumi community, namely by providing a free health care system through the implementation of CETEK program (Cukup E-KTP dan Kartu Keluarga).

This hospital is planning to develop an integrated information system, and implement it so that there is integration between the health services provided, to make it easier to observe and accelerate patient services. Information on doctor schedules and hospital services are published on social media including Facebook and printed media such as banners and leaflets in the information corner.

From the description above, we assess that there is the importance to carry out this study to understand the role of hospital management information systems in improving the 
quality of patient services, especially for patients in hospitals, used as units of this analysis.

\section{RESEARCH METHODS}

This study uses a qualitative descriptive method, by analyzing the implementation of a hospital management information system based on patient services. This research is conducted at Al-Mulk Hospital, Sukabumi City, Indonesia. This hospital is a first level Referral Hospital, both from the district and the local Community Health Center (Puskesmas). In this study, data collection was conducted by utilizing informants, which consist of hospital managers and patients. Data from managers are important to obtain information about hospital management information system. Meanwhile data obtained from the patients is connected with the role of the information system provided by the hospital on the perceived quality of service.

\section{MANAGEMENT InFormation System AND PATIENTS}

The main objective of hospital existence is to serve people who need it. Thus, the development of a hospital is determined by how well the hospital can serve the community, in this case the patient. Patients are the primary consumers of a hospital, however the internal human resources (HR) of the hospital, both medical and non-medical personnel, are internal consumers who must also be served well by the hospital, including hospital managers. In their working life, hospital human resources must work effectively and efficiently in an effort to achieve organizational goals.

In supporting the success of hospital management to achieve its goals effectively and efficiently, the role of information technology is a must. Interconnection between parts in a hospital becomes easier, faster and more accurate. Lakhoua [1] and Nkanata, et al. [2] from the results of his research stated that technology and information systems play a very important role in improving the quality of hospital services.

The successful implementation of this hospital information system is partly determined by human factors [3]. No matter how sophisticated the available information technology is, if it is not supported by the capabilities and expertise of human resources in using the technology, the added value of the technology will not be achieved optimally. Therefore, the capabilities and expertise of human resources are very important in relation to the implementation of the hospital management information system.

One of the goals of the hospital information system is to improve the quality of services for patients or their families, by providing convenience, speed and timeliness of services, as well as accuracy in providing services towards the best for health service users in the hospital.

The service quality of a hospital is very important [4-8]. In the context of a hospital, the quality of service in question is measured by the patient's perception. Parasuraman et al. [9] introduced the quality of service as "SERVQUAL". SERVQUAL has dimensions, namely tangibles, reliability, responsiveness, assurance, and empathy. In relation to the objectives for the success of this service quality, the hospital continues to implement technological advances, including as stated in a study by Lu et al. [10], using hospital electronic information management systems (HEIMS).

\section{MANAGEMENT INFORMATION SYSTEM TO IMPROVE PATIENT SERVICE QUALITY}

The information system developed by the researched hospital is in an effort to improve the quality of services, including to patients. The information system developed is aimed at improving operational processes to make them more efficient and effective, increasing the efficiency of medical services, minimizing medical errors, and is basically based on improving the quality of patient care, where these patients are the main or primary consumers of a hospital. The model of interactive information system show in figure 1.

\begin{tabular}{|c|}
$\begin{array}{c}\text { Human/Computer } \\
\text { Interface }\end{array} \longleftrightarrow \begin{array}{l}\text { Application } \\
\text { Operations }\end{array}$ \\
\hline
\end{tabular}

Fig. 1. Model of interactive information system [11].

Good quality service, in reality, has the potential to increase patient safety and satisfaction. This means that with the availability of the required information system, the hospital's efforts to provide the best quality of service can be realized. In this study, to determine the level of patient satisfaction, an empirical satisfaction survey was carried out using primary data, both aimed at patients in emergency services (IGD), outpatient, and inpatient services. Regarding the improvement of service quality, the hospital has made changes both in terms of physical and non-physical infrastructure, including physical buildings and other facilities, health facilities, and the status of the type of hospital.

The researched hospital possesses a number of missions, namely: (a) providing comprehensive and holistic health services with reference to improving the quality of service and patient safety. (b) creating a harmonious working atmosphere and improving the quality of professional human resources, (c) improving service technology in accordance with scientific developments that are affordable to the community, and d) providing a safe and comfortable hospital atmosphere. The mission is in line with the hospital's strategy in improving the quality of its services continuously, namely through the implementation of hospital information system technology. The hospital's efforts to provide the best service are in accordance with its motto, namely providing fast, precise and humane health services.

The information system in this hospital is still undergoes continuous development as an effort to achieve an integrated information system. From the research results regarding the implementation of management information systems in relation to improving the quality of patient care, with reference to the 
dimensions of service quality which include aspects of physical evidence, reliability, responsiveness, assurance, and empathy are described below. From the dimensions of physical evidence or physical infrastructure and non-physical infrastructure, efforts are still being made to increase the provision, making it easier for patients as primary consumers to get health services. The service reliability dimension refers to the accreditation quality standard, namely by using the service response time standard. Another dimension is assurance, namely with the help of information system technology, the services provided are easier, faster, and more accurate. In terms of the empathy dimension, with the support of information technology and the role of humans remains the most important, namely by providing services to patients with a touch of empathy and strengthening services by promoting human values.

\section{CONCLUSION}

In the existing conditions, the implementation of information system in the researched hospital has not been optimally integrated, therefore efforts are continuously being made by the hospital to develop an integrated information system technology, so that their level of service quality can be further improved. With the development of a hospital information system that has been implemented, it has played a role in the efficiency of medical services, which also means improving the quality of patient care. The better quality of service is assessed by patients from the existence of a faster service time in the sense of efficiency and accuracy because it can minimize service errors. Therefore, the hospital consistently strives to make improvements to increase patient service satisfaction, one of which is the development of a better service information system.

\section{ACKNOWLEDGMENT}

Researchers would like to thank Budget Implementation List, Deputy for Research and Development Enhancement,
Ministry of Research and Technology/Department of National Research and Innovation that have funded this research.

\section{REFERENCES}

[1] N. Lakhoua, "Review on Smart Hospital Management System Technologies,” Res. Sci. Today, no. 1, pp. 187-194, 2019.

[2] M.G. Nkanata, E.O. Makori, and G. Irura, "Comparative analysis of hospital information management systems among healthcare workers in two selected hospitals in Kenya," Libr. Philos. Pract., p. 0_1, 2018.

[3] M. Farzandipur, "Factors affecting successful implementation of hospital information systems," Acta Inform. Medica, vol. 24, no. 1, p. $51,2016$.

[4] M. Shafiq, M. A. Naeem, Z. Munawar, and I. Fatima, "Service quality assessment of hospitals in Asian context: An empirical evidence from Pakistan," Inq. J. Heal. Care Organ. Provision, Financ., vol. 54, p. $0046958017714664,2017$.

[5] S. Lee and E.-K. Kim, "The effects of Korean medical service quality and satisfaction on revisit intention of the United Arab Emirates government sponsored patients," Asian Nurs. Res. (Korean. Soc. Nurs. Sci)., vol. 11, no. 2, pp. 142-149, 2017.

[6] E. Aydemir and Y. Sahin, "Evaluation of healthcare service quality factors using grey relational analysis in a dialysis center," Grey Syst. Theory Appl., 2019.

[7] B. Pouragha and E. Zarei, "The effect of outpatient service quality on patient satisfaction in teaching hospitals in Iran," Mater. Sociomed., vol. 28, no. 1, p. 21, 2016.

[8] M.A. Abbasi-Moghaddam, E. Zarei, R. Bagherzadeh, H. Dargahi, and P. Farrokhi, "Evaluation of service quality from patients' viewpoint," BMC Health Serv. Res., vol. 19, no. 1, pp. 1-7, 2019.

[9] A. Parasuraman, V.A. Zeithaml, and L. Berry, "SERVQUAL: A multiple-item scale for measuring consumer perceptions of service quality," 1988, vol. 64, no. 1, pp. 12-40, 1988.

[10] L.L. Zhou, J. Owusu-Marfo, H.A. Antwi, M.O. Antwi, A.D.T. Kachie, and S. Ampon-Wireko, "Assessment of the social influence and facilitating conditions that support nurses' adoption of hospital electronic information management systems (HEIMS) in Ghana using the unified theory of acceptance and use of technology (UTAUT) model," BMC Med. Inform. Decis. Mak., vol. 19, no. 1, pp. 1-9, 2019.

[11] A.I. Wasserman, "Interactive development environments for information systems," in Implementing Health Care Information Systems, Springer, 1989, pp. 296-312. 